\title{
Genetics components of rice root architecture and carbon isotopic fractionation parameters: a tracer for breeding in a water saving irrigation \\ management
}

Giovani Brito ( $\square$ giovani.brito@embrapa.br)

EMBRAPA Algodão https://orcid.org/0000-0002-4779-9505

Germani Concenço

Embrapa Clima Temperado

Vladimir Eleodoro Costa

UNESP: Universidade Estadual Paulista Julio de Mesquita Filho

Paulo Ricardo Reis Fagundes

EMBRAPA Centro de Pesquisas Agropecuarias do Clima Temperado

João Luis Silva-Filho

Embrapa Algodão

José Maria Barbat Parfitt

EMBRAPA Centro de Pesquisas Agropecuarias do Clima Temperado

Ariano Magalhães

EMBRAPA Centro de Pesquisas Agropecuarias do Clima Temperado

Giovana Tavares Silva

Universidade Federal de Pelotas

Thaís Murias Jardim

Universidade Federal de Pelotas

Nathália Furtado Luccas

Universidade Federal de Pelotas

Walkyria Bueno Scivittaro

EMBRAPA Centro de Pesquisas Agropecuarias do Clima Temperado

Original Article

Keywords: Oryza sativa, physiological breeding, AWD, water-saving irrigation, carbon fractionation

Posted Date: February 4th, 2021

DOI: https://doi.org/10.21203/rs.3.rs-187585/v1 
License: (c) (i) This work is licensed under a Creative Commons Attribution 4.0 International License. Read Full License

Version of Record: A version of this preprint was published at Journal of Crop Science and Biotechnology on August 5th, 2021. See the published version at https://doi.org/10.1007/s12892-021-00109-1. 


\section{Abstract}

Phenotyping is the major bottleneck in the effort to develop varieties of rice (Oryza sativa $\mathrm{L}$ ) suitable for grow under a water saving irrigation management, such as alternate wetting and drying irrigation technique (AWD). In order to analyze if the genotypic variability for carbon isotope discrimination (CID) in rice leaves could be used as a relatively high-throughput tracer to early select superior genotypes highlighting improved root architecture traits when submitted to AWD, a set of twenty varieties grown under semi-natural conditions were submitted to two water irrigation regimes, continuous flooding (CF) and AWD cycles. Coefficients of genetic variance $\left({ }^{\pi} \mathrm{g} g\right.$ ) obtained for root architecture, micro-morphological and physiological traits were significant for all of them regardless of adopted irrigation system, except to mean root diameter. The three significant principal components (PCs) with eigenvalue $>1$, explain the most of the total variation across cycles and water regimes. For most of analyzed traits, the values of heritability coefficients were higher regardless of adopted irrigation management and trait category; for CID, the magnitudes of broad heritability at individual level (greater than 0.80) were similar in the two irrigation techniques, evidencing that the success of selection is independent of irrigation management. The higher CID values after three AWD cycles are associated to varieties with higher total root length and volume. To our knowledge, this is the first study demonstrating the potential application of CID as tracer to select root architecture traits in rice when water-saving irrigation management are of concern.

\section{Introduction}

A challenge of the current agriculture is to feed more than nine billion people in the next decades (Jacquemin et al. 2013; Fan and Brzeska 2014). Additionally, this challenge takes an even greater dimension if taken into account the negative effects of climatic changes predictions on annual rainfall regime, mean temperatures, heat waves, changes in pests dynamics and its acclimation, global change of atmospheric $\mathrm{CO}_{2}$, ozone and sea levels (Brito et al. 2010; Diola et al. 2011; Raza et al. 2019).

Predictions on the impact of these extreme climatic events on global population remain unclear; there are strong evidences, however, that its occurrence will probably influence plant species distribution and physiological resilience ability in specific environments, consequently affecting its productivity. Taken together the above mentioned topics and considering that rice (Oryza sativa L.), is a staple food for billions, the current use of up to $2500 \mathrm{~L}$ of water per $1 \mathrm{~kg}$ of rice produced (Bouman 2009) is almost unacceptable and justifies efforts in development of techniques for most rational water use. One of the tools to contribute for this aim is the construction of plant ideotypes specifically more efficient in water use.

In this sense, to allow farmers to either reduce water demand for rice paddy irrigation or to save water for other purposes, some water-saving irrigation techniques have been developed. AWD irrigation technique is one such technology, developed in the 1990s by the International Rice Research Institute (IRRI) (Price et al. 2013). In summary, when AWD is adopted, water management is carried out via intermittent flooding, which alternates cycles of saturated and unsaturated soil conditions. Under this management, during specific development phases and time, the water entry is closed allowing it to subside until the soil 
reaches a threshold of water potential, after which the field is reflooded. In this context, the adoption of AWD in rice paddies could be used to increase water use efficiency and the same time, reduce energetic costs involved in water capture, pumping and distribution, compared to the traditionally made by most farmers that adopt the continuous flooded system. Refinements in AWD could lead to an alternative for farmers to face the negative impacts of climate change on rain distribution regime in the future, besides contributing to decrease rice production costs.

Different studies has highlighted that the impacts of high water use by continuously flooded systems can be addressed with the implementation of AWD, but in many cases yields are reduced when this techniques is adopted (Carrijo et al. 2017). Meta-analysis carried out by these authors showed that the degree of soil drying during the drying cycles was critical to ensuring that yields were kept high. Additionally, they reported that with mild AWD managements, where soil water tension at root depth were below $20 \mathrm{kPa}$ or where the water table in sub-superficial irrigation did not drop below $15 \mathrm{~cm}$ in soil depth, not significantly reduced rice grain yield. On the other hand, severe yield losses were verified at AWD where the soil water tension at root depth was beyond $20 \mathrm{kPa}$. In this sense, physiological breeding could elucidate the mechanisms involved in the plant responses during alternate wetting and drying cycles, leading to definition of some physiological tracer to supply the rice breeding programs with a tool to identify suitable genotypes to obtain cultivars better adapted to AWD management, without penalizing grain quality and productivity. The scarcity of suitable phenotyping protocols is a major bottleneck for rice breeding progress in the achievement of superior genotypes for AWD, what could increase the adoption of this technique by farmers. Physiological traits known to contribute to increase the plant performance under AWD are laborious to quantify and require resource intensive procedures to be measured; thus, unsuitable for some of the early stages of a breeding program where thousands of genotypes should be screened. Among these, stomatal conductance coordination, root and shoot plasticity and photosynthesis rate, besides the ability to develop deep roots, comprises important contributors for the improvement of plant responses under limited water availability.

There is a large set of information reporting contribution of certain root architecture traits and robustness leading to improvements in plant performance under drought, regardless of their constitutive or inducible expression way. Under different drought degrees and plant development phase, plasticity in root length and volume or even in mean diameter has been associated to increases in plant gas exchange performance, biomass production and even grain yield (Weber et al. 2014; Sandhu et al. 2016; Brito et al. 2019).

Carbon isotope discrimination (CID) has been extensively used as a proxy for physiological breeding of many plant species, aiming to improve its water use efficiency or its effective capacity of water use under dryland condition (Farquhar and Richards 1984; Farquhar et al. 1989; Brito et al. 2014; Dixon and Carter 2019). Nevertheless, there is scarce knowledge about its usability to identify desirable genotypes when AWD is adopted; especially considering the soil dynamic changes created by AWD and its complex interactions among genotypes. As proposed by Farquhar and Richards (Farquhar and Richards 1984), plants with $\mathrm{C}_{3}$ metabolism discriminate against ${ }^{13} \mathrm{C}$ in favor of ${ }^{12} \mathrm{C}$ during the conversion of $\mathrm{CO}_{2}$ into 
carbohydrates. According to these authors, the comparison of plant isotopic composition among and between species led to definition of CID, which was defined as the deviation from unity of atmospheric ${ }^{13} \mathrm{C} /{ }^{12} \mathrm{C}$ divided by plant ${ }^{13} \mathrm{C} /{ }^{12} \mathrm{C}$. The main efforts to understand the drivers of carbon isotopic discrimination led to the finding that $\mathrm{CID}$ shares a positive and linear relationship with the ratio of internal leaf $\mathrm{CO}_{2}\left(\mathrm{C}_{\mathrm{i}}\right)$ and the atmospheric $\mathrm{CO}_{2}$ concentrations $\left(\mathrm{C}_{\mathrm{a}}\right)$ (G D Farquhar et al. 1989). This is strongly impacted by stomatal conductance and photosynthetic performance, what allow researchers to make conclusions regarding principles of plant physiology from CID analysis (Brugnoli et al. 1988). When considered gas exchange performance over time, especially for photosynthesis and stomatal conductance in the tissue, where these parameters are analyzed, a high CID in leaf may be assumed to have experienced high stomatal conductance with low photosynthetic capacity or high performance for stomatal conductance and high photosynthesis, whereas the opposite may be assumed for low CID in plant tissue (Dixon and Carter 2019). Taken together, these assumptions and mode of dynamic progress of flooding and drying cycles via AWD, could lead to identify and classify genotypes based in traits known to be related to water deficit tolerance. But if considered the labor and time demanded to do direct phenotyping such as root robustness and architecture, deep roots assessment, stomatal conductance and anatomical plasticity, the leaf CID plasticity can serve as an initial practical and feasible tool for screening genotypes exhibiting these traits. At follow, preliminary data for the use of leaf CID as tool for breeding programs are highlighted, aiming to establish them as a potential tracer in plant ideotype construction for the AWD technique.

\section{Material And Methods}

Genetic material and growth conditions

A trial test was conducted under semi-natural conditions using a structure facility constructed specifically for this purpose (Figure 1). The study was accomplished during the 2019/2020 cropping season, at LowLand Embrapa Experimental Station, located near Pelotas city, Rio Grande do Sul state, Brazil. Soil from this region is classified as Haplic Planosol (Albaqualf) (Santos et al. 2018), with geographic coordinates $\left(31^{\circ} 46^{\prime} 19^{\prime \prime} \mathrm{S}, 52^{\circ} 20^{\prime} 33^{\prime \prime} \mathrm{W}\right), 17 \mathrm{~m} \mathrm{ASL}$, a traditional region for rice production under continuous flooding. Detailed description of the facility structure will be described in the next subtopic.

The analyzed data sets were collected from a set of 20 genotypes (table 1) consisting of rice traditional varieties and elite breeding lines from the breeding program of Brazilian Agricultural Research Corporation (Embrapa), plus a hybrid (XP 113) from a private company.

Table 1 Genetic materials and genealogy of crosses made between conventional parents, with the respective status within breeding program, origin, genotype per cross e subtype plants used for the study 


\begin{tabular}{|c|c|c|c|c|c|}
\hline Genotypes & Status & Origin. & Cross combination & Year & type \\
\hline AB 14738 & Line & Embrapa & BRA Pampa x Irga 424 & 2014 & Indica \\
\hline BRA 050151 & Line & Embrapa & BRS 7 Taim/CL Sel 720 & 2005 & Indica \\
\hline BRS 358 & Cultivar & Embrapa & GIZA 175/ MILYANG 49 & 2016 & Japonica \\
\hline BRS A705 & Cultivar & Embrapa & BRA 01016/CNAi10393 & 2020 & Indica \\
\hline BRS Firmeza & Cultivar & Embrapa & BR IRGA 411/BLUEBELLE // LEMONT & 1999 & Indica \\
\hline BRS Pampa CL & Cultivar & Embrapa & BRS Pampa (3)/Puitá INTA CL & 2019 & Indica \\
\hline BRS Pampeira & Cultivar & Embrapa & IR 22/CNA 8502 & 2016 & Indica \\
\hline CNA 1003 & Progeny S0:3 & Embrapa & Multiples (Pop. SR CNA 11) & 2010 & Indica \\
\hline CNA 1120 & Progeny S0:3 & Embrapa & Multiples (Pop. SR CNA 11) & 2011 & Indica \\
\hline CNA 1121 & Progeny S0:3 & Embrapa & Multiples (Pop. SR CNA 11) & 2011 & Indica \\
\hline СТВ 1419 & Progeny F5 & Embrapa & Sel. TB 1211-2/IRGA 424 & 2014 & Indica \\
\hline CTB 1444 & Progeny F5 & Embrapa & Sel. TB 1211-1 BRA 051108 & 2014 & Indica \\
\hline СТВ 1455 & Progeny F5 & Embrapa & Sel. TB 1211-5/BRA 051077 & 2014 & Indica \\
\hline LTB 13016 & Line & Embrapa & BRS Firmeza/BRS Agrisul & 2013 & Indica \\
\hline LTB 13036 & Line & Embrapa & BRA 050055/BR-IRGA 409 & 2013 & Indica \\
\hline LTB 14002 & Line & Embrapa & BRS Atalanta/Oro & 2014 & Indica \\
\hline LTB 17033 & Line & Embrapa & CL 113-4-1-1/CL 591 & 2017 & Indica \\
\hline LTB SEL $\quad 1211-2$ & Line & Embrapa & CL 113-4-1-1/CL 591 & 2012 & Indica \\
\hline LTB SEL $1211-3$ & Line & Embrapa & CL 113-4-1-1/CL 591 & 2012 & Indica \\
\hline XP 113 & Hybrid & Rice Tec & Confidencial information & 2015 & Indica \\
\hline
\end{tabular}

The BRS Pampa CL, BRS 358 cultivars and AB 14738 elite line were selected based on results from a field study conducted by Brito and co-workers (Brito et al. 2019), where BRS Pampa showed a positive plasticity for total root volume and root length, whereas a negative plasticity was found for BRS 358 and $A B$ 14738. The set of additional genotypes were included based on its use by regional farmers or as result of grain yield performance in field assessments by Embrapa's Rice Breeding Program. Sowing was accomplished in rows spaced in $0.175 \mathrm{~m}$ with $1 \mathrm{~m}$ long, thinned to density of 300 plants $\mathrm{m}^{-2}$ ten days after emergence. The set of genotypes used were similar for maturity group (125-135 days from emergence to maturity). Sowing was accomplished in September $23^{\text {th }}, 2019$, emergence occurred in October $02^{\text {nd }}, 2019$.

Topdressing fertilization consisted of $100 \mathrm{~kg} \mathrm{ha}^{-1}$ of $\mathrm{N}$ as commercial urea split in two applications: $70 \%$ of the dose was applied at the beginning of tillering of the plants (20 days after emergence - DAE), prior to flooding, and the remaining $30 \%$ of the dose was applied nearby to panicle initiation. This stage was estimated by using the software PlanejArroz (Steinmetz et al. 2020) by supplying location, emerge date and indicating BRS Pampa CL, a commercial variety with similar cycle length to the evaluated set of genotypes. Soil chemical parameters are shown in Table 02.

Table 2 Soil chemical characteristics from $0-20 \mathrm{~cm}$ of the soil layer in Estação Experimental Terras Baixas (EETB), Embrapa Temperate Agriculture, Pelotas, RS, Brazil. 


\begin{tabular}{|c|c|c|c|c|c|c|c|c|}
\hline EЕTB & O.M. & $\mathrm{pH}$ & $\mathrm{P}$ & $\mathrm{K}^{+}$ & $\mathrm{Ca}^{2+}$ & $\mathrm{Mg}^{2+}$ & $\mathrm{Al}^{3+}$ & Clay \\
\hline Sample* & $\mathrm{g} \mathrm{dm}^{-1}$ & water & ----- r & $\mathrm{lm}^{3}$ & -------- & $\mathrm{ol}_{\mathrm{C}} / \mathrm{c}$ & ----- & $\mathrm{g} \mathrm{dm}^{-1}$ \\
\hline 22894 & 15 & 5.2 & 1.9 & 43.0 & 1.2 & 1.1 & 0.7 & 170 \\
\hline
\end{tabular}

* Analysis were carried out according to Tedesco and co-workers (Tedesco et al. 1995)

The study comprised two water managements consisting of a well-watered set of plots, where plants were maintained under continuous flooding (control), and another treatment submitted to Alternate wetting and drying management (AWD) (stressed) imposed from $\mathrm{V}_{4}$ plant stage (Counce et al.

2000) onwards (Price et al. 2013), consisting of three intermittent cycles of irrigation. A set of rectangular $500 \mathrm{~L}$ fiberglass water tanks was arranged in a split-plot design, with water treatments as the main plots and genotypes as subplots, in three replications. From rice sowing to the beginning of tillering, all plots were irrigated daily to keep soil moisture near field capacity. At tillering, a five cm flood depth was established for each plot and maintained under continuous flooding by 10 consecutive days.

Subsequently, for each cycle of intermittent irrigation, those plots submitted to AWD were drained and not irrigated again, being monitored until soil water tension reached $20 \mathrm{kPa}$ (7-11 days depending on prevalent climatic conditions), when the first AWD cycle was completed. At this water tension, plots were re-irrigated with a new five $\mathrm{cm}$ flood depth, and maintained by $72 \mathrm{~h}$. Subsequently, a new AWD cycle was started by controlled drainage via independent valve-controlled water inlets and outlets of each plot. Three intermittent irrigation cycles were sequentially imposed. The progress of soil water tension was monitored by installing two Watermark sensors (Irrometer inc., USA) per plot at $10 \mathrm{~cm}$ depth, wired to electronic data loggers for continuous follow up on soil water status. Data were reviewed twice a day and mean values, excluding outliers, was used to define the time for re-irrigation at the end of each intermittent cycle (Figure 1).

Facility structure and measured phenotypic traits

Aiming an efficient control of the intermittent irrigation cycles for AWD treatment, a specific facility structure was idealized and constructed to allow the establishment of good plant growth conditions and, at same time, especially designed to permit the control of uniform drainage during application of AWD (Figure 1). This structure created the adequate conditions for applying the AWD technique due to the efficient control of water inlets and outlets, including the water layer height, and uniformity in the rapid drainage for AWD.

Figure 1 Overview of a low-cost structure facility specifically designed and constructed for monitoring and efficient control of the alternate wetting and drying cycles during the study; red arrows indicate rainwater reservoir (1), data loggers for soil tension monitoring and logging (2), float-controlled layer valve (3), water inlet controller (4) and water drainage controller (5)

Briefly, this structure consisted of a set of fiberglass tanks connected by PVC pipes to a $5000 \mathrm{~L}$ water reservoir fed by rainwater collected on the rooftops of two adjacent greenhouses. This set of rectangular $500 \mathrm{~L}$ fiberglass water tanks was equipped with independent valve-controlled water inlets and outlets for 
precise irrigation and drainage as needed. These tanks were filled with a $5 \mathrm{~cm}$ layer of crushed stone followed by a $5 \mathrm{~cm}$ layer of coarse sand and, $50 \mathrm{~cm}$ layer of soil previously corrected and fertilized for rice (SOSBAI 2018). Soil was collected from a nearby area, with long history of rice cultivation under continuous flooding. The soil was collected between 0 and $20 \mathrm{~cm}$ depth, which represents the average root depth in local soils. Water layer height was controlled via installation of a float valve for each tank. For uniform and fast drainage, a perforated $25 \mathrm{~mm}$ PVC pipe with $70 \mathrm{~cm}$ long $(5 \mathrm{~cm}$ higher than the height of the tank wall) were installed in the center of each tank in order to avoid the formation of water pockets into soil during application of the intermittent irrigation cycles, standardizing the drainage procedures. Water re-entry into the system after a drainage cycle occurred when the watermark sensors of the plot indicated $20 \mathrm{kPa}$ of soil water tension (Pinto et al. 2016; Pinto et al. 2020).

A set of twenty genotypes consisting of modern cultivars, progenies, lines and a hybrid grown under seminatural conditions, submitted to two water irrigation regimes (AWD cycles and continuous flooding), were evaluated to assess the variation in phenotypic traits. In total, 24 phenotypic traits/derivatives, distributed in three categories (Root architecture, physiological/shoot morphological and micro-morphological traits), were evaluated during plant vegetative phase (Table 3 ). 
Table 3 List of analyzed and derived phenotypic traits broadly classified into three categories (A-C) with trait acronyms and units

Trait

Trait acronym

Unit

\section{Root architecture traits}

Total root length $(\mathrm{cm})$

Total root length under continuous flooding in first cycle

TRL in CF $-1^{\text {st }}$ cycle $\quad \mathrm{cm}$

Total root length under continuous flooding in second cycle

TRL in CF $-2^{\text {nd }}$ cycle $\quad \mathrm{cm}$

Total root length under continuous flooding in third cycle

TRL in CF $-3^{\text {rd }}$ cycle $\quad \mathrm{cm}$

Total root length under alternate wetting drying in first cycle

TRL in AWD $-1^{\text {st }}$ cycle $\quad \mathrm{cm}$

Total root length under alternate wetting drying in second cycle

TRL in AWD $-2^{\text {nd }}$ cycle $\quad \mathrm{cm}$

Total root length under alternate wetting drying in third cycle

TRL in AWD - $3^{\text {rd }}$ cycle

$\mathrm{cm}$

Total root volume

Total root volume under continuous flooding in first cycle

TRV in CF $-1^{\text {st }}$ cycle $\quad \mathrm{cm}^{-3}$

Total root volume under continuous flooding in second cycle

TRV in CF $-2^{\text {nd }}$ cycle $\quad \mathrm{cm}^{-3}$

Total root volume under continuous flooding in third cycle

TRV in CF - $3^{\text {rd }}$ cycle $\quad \mathrm{cm}^{-3}$

Total root volume under alternate wetting drying in first cycle

TRV in AWD - $1^{\text {st }}$ cycle $\quad \mathrm{cm}^{-3}$

Total root volume under alternate wetting drying in second cycle

TRV in AWD - $2^{\text {nd }}$ cycle $\quad \mathrm{cm}^{-3}$

Total root volume under alternate wetting drying in third cycle

TRV in AWD $-3^{\text {rd }}$ cycle $\quad \mathrm{cm}^{-3}$

Mean root diameter

Mean root diameter under continuous flooding in first cycle

MRD in CF $-1^{\text {st }}$ cycle $\quad \mu \mathrm{m}$

Mean root diameter under continuous flooding in second cycle

MRD in CF $-2^{\text {nd }}$ cycle $\quad \mu m$

Mean root diameter under continuous flooding in third cycle

MRD in CF - $3^{\text {rd }}$ cycle $\quad \mu \mathrm{m}$

Mean root diameter under alternate wetting drying in first cycle

MRD in AWD $-1^{\text {st }}$ cycle $\quad \mu m$

Mean root diameter under alternate wetting drying in second

cycle

MRD in AWD $-2^{\text {nd }} \mu \mathrm{m}$

cycle

Mean root diameter under alternate wetting drying in third cycle $\quad$ MRD in AWD - $3^{\text {rd }}$ cycle $\quad \mu m$

\section{(B) Physiological and shoot morphological traits}

Carbon isotope discrimination under continuous flooding

CID in $\mathrm{CF}$

(

Carbon isotope discrimination under alternate wetting drying

CID in AWD

]

Shoot dry weight under continuous flooding

Shoot DW in CF

g

Shoot dry weight under alternate wetting drying

Shoot DW in AWD

g

\section{(C) Micro-morphological traits}

Stomatal density

SD

$\mathrm{n}$ 을 $\mathrm{mm}^{-2}$

Stomatal pore width

SPW

$\mu \mathrm{m}$ 
An isotopic mass spectrometer at the Stable Isotopes Center of the Universidade Estadual Paulista UNESP, Brazil was used to determine the leaves carbon isotope percentages. Leaves samples were dried in an oven at $50^{\circ} \mathrm{C}$ for $48 \mathrm{~h}$ to homogenized in a cryogenic mill (Geno / Grinder 2010 - SPEX SamplePrep, USA) using liquid nitrogen at $-196^{\circ} \mathrm{C}$. A 50 to $70 \mu \mathrm{g}$ aliquot of each sample was weighed in a tin capsule using a $1 \mu \mathrm{g}$ resolution scale (XP6 - Mettler Toledo, Switzerland). The homogenization of the samples increases the representativeness of the small sample rate. The capsules were analyzed in a CF-IRMS continuous-flow isotope ratio spectrometry system using an IRMS (Delta V Advantage, Thermo Scientific, Germany) coupled to an Elemental Analyzer (Flash 2000, Thermo Scientific, Germany) using a gas interface (ConFlo IV, Thermo Scientific, Germany). The CF-IRMS determined the isotopic ratio of Carbon $R$ $\left({ }^{13} \mathrm{C} /{ }^{12} \mathrm{C}\right)$ and the values were expressed in relative difference of the isotopic ratio $\left(\delta^{13} \mathrm{C}\right)$, in $\mathrm{mUr}$ (Brand and Coplen 2012), from the V-PDB standard according to the equation 1 (Coplen 2011). The standard uncertainty of the CF-IRMS is $\pm 0.15 \mathrm{mUr}$ and the results were normalized from the IAEA-NBS-22 standard, as shown by the following formula: $\delta^{13} \mathrm{C}=\left[R\left({ }^{13} \mathrm{C} /{ }^{12} \mathrm{C}\right)_{\text {sample }} / R\left({ }^{13} \mathrm{C} /{ }^{12} \mathrm{C}\right)_{\mathrm{VPDB}}\right]-1$. For carbon isotopic discrimination $(\Delta)$, the following formula was used: $\Delta=\left(\delta^{13} \mathrm{Ca}-\delta^{13} \mathrm{Cp}\right) /\left(1+\delta^{13} \mathrm{Cp}\right)$, where $\delta^{13} \mathrm{Ca}$ and $\delta^{13} \mathrm{Cp}$ are the carbon isotope compositions of atmosphere and plant samples, respectively (Farquhar et al. 1989). As a convention, the $\delta^{13} \mathrm{Ca}$ values was assumed to be $-8.0 \mathrm{mUr}$ (Hall et al. 1994). As pointed before, carbon isotope composition values at most of time expressed in terms of 'per mil' aiming indicate that the original value was multiplied by $10^{3}$.

Root sampling and image analysis

At the end of each of the three AWD cycles, three plants per genotype were randomly collected independent of applied irrigation system. For this propose, a whole plant core sampler $(50 \mathrm{~mm}$ diameter by $70 \mathrm{~cm}$ long) tube, inserted from the top to the bottom of the cultivation tanks. Subsequently, the whole plants (shoots and roots) were individually prepared; samples consisted of shoot and roots, separated by means of a cut in the crown region aiming facilitate its washing and whitening. Subsequently, these roots were taken to the photographic studio of Embrapa Temperate Agriculture to obtain the root images; these were then placed into a black-bottomed plastic tray containing a water film approximately $2 \mathrm{~mm}$ thick, thus facilitating root dispensal. Roots were spread evenly with the aid of tweezers to avoid root overlapping in the photography. Images was captured by using a Canon EOS 7D photographic camera, $40 \mathrm{~mm}$ lens, at a fixed distance of $1.20 \mathrm{~m}$ from the target, positioned in an L-shaped support, using LED lighting.

From the obtained root images, morphometric parameters were analyzed by using the software WinRHIZO PRO 2013a (Regent Instruments. Inc., Quebec, Canada). Mean root diameter, total root volume and total root length were quantified and considered for calculation of root architecture traits. 
Leaves were collected 23 days after emergence during the first AWD irrigation cycle. For measurements, immediately after cutting, the middle section of the adaxial (upper) face of the second leaf was observed and photographed via an optical microscope (Nikon e200) with $0.5 \mathrm{x}$ magnification for camera and $40 \mathrm{x}$ for microscope objective lens. Leaf sections were gently pressed between two microscope glass slides, held tight together by adhesive tapes, to keep leaf flat open. Photography scales were set by previously capturing images of a microscope calibration ruler, in both magnifications. Subsequently, two images with resolution of $2048 \times 1536$ pixels (3.1 MP) were randomly taken per leaf for analysis.

Captured images were saved in hierarchical naming structure for later processing via the software Image J v.1.53c $(\mathrm{NIH}, 2020)$. After software scale calibration, the stomatal density and stomatal pore width (20 x magnification) were quantified by using software tools. Stomatal related data were obtained after applying the filter "relief" to the images to increase stomatal border and opening contrasts. Stomatal density was quantified in an area correspondent to $25 \%$ of the captured image, as this was the area into each picture where the microscope was better focused; this area was appropriately considered in stomatal density calculations. Scales were marked into images by ImageJ software.

\section{Statistical Procedures}

For estimation of genetic parameters were used the 'R package sommer'(Covarrubias-Pazaran 2016; Covarrubias Pazaran 2018). Firstly, individual analysis were carried out for each irrigation system; genotypes being considered as random effects, testing the significance of the genetic variance $\left(\sigma^{2}{ }_{g}\right)$ and residual variance $\left(\sigma_{\mathrm{e}}^{2}\right)$ components via Wald test (Z ration). Additionally, estimate of broad sense heritability $\left(\mathrm{h}^{2}\right)$ at individual level were done according to (Holland 2006). An univariate unstructured variance model, in which consider the genotypes as random effect and irrigation system as fixed effect were used to estimation of co-variances with subsequent calculation of genetic correlations to a same variable in the two irrigation systems. The test procedures adopted for genetic correlations were identical those used for heritability calculations. All used procedures are integrated into the R Core Team (Core R Team 2020).

The heatmap was constructed using the R package Pheatmap' (Kolde 2019); variables were standardized individually being the distance between variables calculated via Pearson's correlation for a given variable in each irrigation system via Ward's test. For genotypes grouping formation, the estimation of Euclidean distances were calculated using Ward's procedures also using Ward's procedures. Taken into account that experiment was comprised by three intermittent irrigation cycles, opted as cut point by three genotypes groups or variables, as shown in Figure 5.

Subsequently, after normality test by Henze-Zinkler, the obtained data were subjected to multivariate statistical approaches, via principal components analysis (PCA) in order to generalize, reduce the overlapping among evaluated variables and characterize the germplasm more comprehensively. This 
statistical approach is extensively used in situations where a large number of variables should be evaluated, allowing into major components and total variation. In order to facilitate the identification of genotype traits which make it possible to differentiate them from the others in terms of root architecture and its derivatives, physiological/morphological shoots and micro-morphological traits, during PCA analysis some procedures were previously determined during the graph scales definitions. For this propose, scale values on the $\mathrm{X}$ axis and on the $\mathrm{Y}$ axis were gradually increased leading to maximum genotypes scattering, without loss of any genetic materials and information. The procedures allow an easy overview of those genotypes that were positioned near the centre. These genotypes are similar and not show significant differences between themselves for evaluated variables. On the other hand, those genotypes positioned near and at extremes of two scales can be thought as differing from the others, with superior characteristics closely associated with their positioning across the biplot graph. As cited by Dallastra and co-workers (Dallastra et al. 2014) these genotypes are those that should receive special attention and are likely to be selected. The choice of principal components was based on eigenvalues higher than one (1.0), as by Kaiser's study (Kaiser 1958). According to this author, eigenvalues greater than this threshold can generate components having a relevant amount of information of the original variables. Multivariate analysis via PCA and data plotting were carried out using tools of the SigmaPlot 14.0, from Systat Software (SigmaPlot Version 14.0).

\section{Results And Discussion}

Estimating genetic variance components and heritability

The authors decide begins showing the genetic components issues because we would have arguments to drive a sequential discussion across of the manuscript, besides help in the definition of used statistical approaches for subsequent phases of the analysis. Coefficients of genetic variance $\left({ }^{\pi 2} \mathrm{~g}\right)$ obtained for root architecture, micro-morphological and physiological traits were significant for all of them (table 4), regardless of adopted irrigation regime, except to mean root diameter at the end of third irrigation cycle for both the water managements. It should be noted that the existence of genetic variability is sine qua non to success of the selection. Thus, the data highlighted the existence of real probability to obtain improvements for evaluated traits, except for mean root diameters in these two conditions. In general, the values of heritability coefficients were higher regardless of adopted irrigation system and trait category (table 3 ). The heritability for shoot dry weight under continuous flooding was greater than under AWD, indicating that the selection is most favorable when carried out under continuous flooding. On the other hand, for carbon isotope discrimination, the magnitudes of heritability were similar in the two irrigation techniques, demonstrating that the success of selection is independent of irrigation technique. Analyzing root architecture traits such as total root length and volume, superior magnitudes of heritability was demonstrated under AWD, pointing that selection of these traits under intermittent irrigation might contribute to success.

Table 4 Estimate of genetic variance components $\left(\sigma_{g}^{2}\right)$, residual variance components $\left(\sigma_{e}^{2}\right)$ and heritability $\left(h^{2}\right)$ in broad sense heritability for analyzed traits in a set of rice genotypes subjected to alternate wetting and drying and to continuous flooding at vegetative phase

Page $12 / 23$ 


\begin{tabular}{|c|c|c|c|c|c|c|c|c|c|c|c|c|}
\hline \multirow[b]{2}{*}{ Traits } & \multicolumn{5}{|c|}{ AWD } & \multicolumn{5}{|c|}{$\mathrm{CF}$} & \multirow{2}{*}{$\begin{array}{c}\mathrm{rg} \\
(\mathrm{AWD}, \mathrm{CF})\end{array}$} & \multirow{2}{*}{$\begin{array}{l}\mathrm{sd} \\
(\mathrm{rg})\end{array}$} \\
\hline & Mean & $\sigma_{g}^{2}$ & $\sigma_{e}^{2}$ & $\mathrm{~h}^{2}$ & $\mathrm{sd}\left(\mathrm{h}^{2}\right)$ & Mean & $\sigma_{g}^{2}$ & $\sigma_{e}^{2}$ & $\mathrm{~h}^{2}$ & $\operatorname{sd}\left(h^{2}\right)$ & & \\
\hline$\overline{\text { CID }}$ & 22,54 & 0,54 ** & 0,07 & 0,883 & 0,042 & 22,95 & 0,2392 ** & 0,0438 & 0,845 & 0,055 & 0,546 & 0,175 \\
\hline MRD - $1^{\text {st }}$ cycle & 272,99 & 0,00 n.s. & 30,92 & 0,000 & 0,131 & 282,09 & $4,24 * *$ & 50,84 & 0,077 & 0,140 & - & - \\
\hline $\mathrm{MRD}-2^{\text {nd }}$ cycle & 270,10 & 0,00 n.s. & 80,92 & 0,000 & 0,131 & 271,74 & $6,31 * *$ & 50,60 & 0,111 & 0,143 & - & - \\
\hline $\mathrm{MRD}-3^{\text {rd }}$ cycle & 269,82 & 0,00 n.s. & 88,09 & 0,000 & 0,131 & 277,53 & 0,00 n.s. & 86,09 & 0,000 & 0,131 & - & - \\
\hline TRL - $1^{\text {st }}$ cycle & 2976 & $223781 * *$ & 18232 & 0,925 & 0,028 & 2942 & 92237 ** & 65842 & 0,583 & 0,118 & 0,104 & 0,250 \\
\hline TRL $-2^{\text {nd }}$ cycle & 2759 & $94043 * *$ & 33930 & 0,735 & 0,086 & 2697 & 40918 ** & 20792 & 0,663 & 0,103 & 0,390 & 0,233 \\
\hline TRL - $3^{\text {rd }}$ cycle & 3074 & 99043 ** & 19590 & 0,835 & 0,058 & 3442 & 107159 ** & 34047 & 0,759 & 0,080 & 0,068 & 0,248 \\
\hline TRV $-1^{\text {st }}$ cycle & 2,451 & $0,0734 * *$ & 0,0362 & 0,670 & 0,101 & 2,460 & 0,1088 ** & 0,0341 & 0,762 & 0,079 & 0,513 & 0,201 \\
\hline TRV $-2^{\text {nd }}$ cycle & 2,146 & $0,0309 * *$ & 0,0137 & 0,693 & 0,096 & 2,117 & $0,0295 * *$ & 0,0244 & 0,547 & 0,125 & 0,080 & 0,276 \\
\hline TRV $-3^{\text {rd }}$ cycle & 2,442 & $0,0781 * *$ & 0,0198 & 0,798 & 0,069 & 2,796 & $0,064 * *$ & 0,028 & 0,696 & 0,096 & 0,170 & 0,249 \\
\hline Shoot DW & 5,33 & $0,8884 * *$ & 0,710 & 0,556 & 0,123 & 6,03 & 2,124 ** & 0,173 & 0,925 & 0,028 & 0,087 & 0,253 \\
\hline SD & 478,88 & 11967 ** & 3983 & 0,750 & 0,082 & & - & - & - & - & - & - \\
\hline SPW & 9,28 & 2,522 ** & 0,453 & 0,848 & 0,054 & & - & - & - & - & - & - \\
\hline
\end{tabular}

** Significant by Wald test $(\mathrm{P} \geq 0.05)$; ns means non-significant. Traits labels are in according to category (uppercase letters) in Table 3; together with their acronyms.

Nevertheless, the success of selection in a given water regime does not guarantee that genetic gains will also be obtained in the other water management, since a premise depends on the magnitude of the genetic correlations between evaluation conditions for a specific trait. In the same way, selection for a specific trait could lead to indirect gains or undesirable losses in others, depending on the magnitude of the present genetic correlations.

Phenotypic traits variation and their interrelations

Multivariate statistical procedures, via principal component analysis (PCA) among root architectures and physiological traits were done across the three irrigation cycles and water irrigation regimes, among the set of genotypes. For total root length (TRL) and their derivatives (Figure 2), this approach identified three significant principal components (PCs) with eigenvalue $>1$, which cumulatively explain approximately $70 \%$ of the total variation for all cycles and water regimes. The first PC represent more than $32 \%$ of the total variation; which is associated with genotypic variation in the majority of this root traits and their derivatives, independently of irrigation cycle and water regimes. The eigenvalue for the second component was 1.7, which was associated with total root length in alternate wetting and drying regime in first irrigation cycle (TRL in AWD $-1^{\text {st }}$ cycle) and TRL in continuous flooding in third irrigation cycle ( $T R L$ in $C F-3^{\text {rd }}$ cycle). Additionally, these derivative variables were correlated with each other, even from distinct irrigation cycle and water regime. This $\mathrm{PC}$ retained a variance proportion greater than $21 \%$, with main variables being carbon isotope discrimination in continuous flooding (CID in CF), TRL in AWD $-1^{\text {st }}$ cycle and TRL in CF $-3^{\text {rd }}$ cycle. For instance, CID in AWD highlighted a positive correlation with TRL in CF $-1^{\text {st }}$ cycle $(r=0.60)$ and CID in CF $(r=0.49)$. Taken together, these results clearly suggest that selecting plants based on CID, independently of the adopted water regime, could result in plants with increased root length. It could reduce the costs involved in their suitability in routines 
of breeding programs, since only a water regime could be enough to select superior genotypes. In Figure 2 , it is also highlighted the dispersion of evaluated traits according to score and the correlation between them. Taken as an example, selecting BRS Pampeira and BRS A705 cultivars and LTB 17033 line, that show high CID in the two water regimes, could result in plants with greater performance for this desirable root trait.

Figure 2 PCA of the eight variables/derivatives involving total root length (TRL in $\mathrm{cm}$ ) at three irrigation cycles and carbon isotope discrimination subjected to two-water regime treatments. The first two components show majority of variation with their vector projections for each trait. Biplot graph highlight the genotypes distribution (in dark blue) across worked scales. The traits marked by circles/ellipses contributed more to the variation explained by PC1, and to the variation explained by PC2. Blue and Red arrows denote carbon isotope discrimination under continuous flooding and under alternate wetting and drying water regimes, respectively; other trait labels are in according to category (uppercase letters) in Table 3;; together with their acronyms

When PCA was used to explain variation for total root volume (TRV) trait/derivatives, three significant principal components (PCs) with eigenvalue $>1$, explaining greater than $59 \%$ of the total variation across cycles and water regime were identified (Figure 3). The first PC represents more than $25 \%$ of the total variation, beind associated to the genotypic variation for TRV in alternate wetting and drying at the first cycle (TRV in AWD $-1^{\text {st }}$ cycle) besides TRV in AWD $-2^{\text {nd }}$ cycle and CID at both irrigation regimes. The eigenvalue for the first and second components were 2.02 and 1.50, respectively. The second PC was associated with total root volume in continuous flooding at the second cycle (TRV in CF $-2^{\text {nd }}$ cycle). Moreover, TRV in AWD $-2^{\text {nd }}$ cycle was closely correlated with CID, regardless of the irrigation regime. This PC retained a variance proportion nearly $19 \%$. For instance, CID in AWD showed positive correlation with CID in CF $(r=0.62)$. Again, high correlation found between CID values in both irrigation regimes clearly indicate that selecting plants based on CID, independently of the adopted water regimes, could result in plants with increased root volume. As pointed before, similarly found to root length, the costs involved in the selection for root volume could be significantly reduced, increasing their usability as a tracer to be included in routine of a breeding program, since only a water regime could be enough to select superior genotypes for this purpose. The Figure 3 supplies an overview of dispersion behavior of evaluated traits according to the score, and the correlation between them. For instance, selecting BRS A705 cultivar and CTB 1455 line with high CID capacity, the total root volume will link them, independently of adopted irrigation technique.

Figure 3 PCA of the eight variables/derivatives involving total root length (TRV in $\left.\mathrm{cm}^{-3}\right)$ at three irrigation cycles and carbon isotope discrimination (CID) subjected to two-water regime treatments. The first two components show majority of variation with their vector projections for each trait. Biplot graph highlight the genotypes distribution (in dark blue) across worked scales. The traits marked by circles/ellipses contributed more to the variation explained by PC1, and to the variation explained by PC2. Blue and Red arrows denote carbon isotope discrimination under continuous flooding and under Alternate wetting and 
drying water regimes, respectively; other trait labels are in according to category (uppercase letters) in Table 3; together with their acronyms

Heat mapping of root architecture and carbon isotope discrimination traits of rice

Taken into account the genetic components analysis (table 4), the mean root diameter (MRD trait and derivatives, which showed non-significant genetic variance) were excluded from the next step, in which heat maps were generated based on standardization of phenotypic values (Figure $5 \mathrm{~A}$ and $\mathrm{B}$ ). Thus, heatmap analysis is indicating a relative performance of a set of genotypes relative to the mean response for a given trait; and according to color scale, the positive dark blue represent those genotypes showing higher performance for a given root architecture and/or micro-morphological and physiological trait (positive values from standard phenotypic procedures).

From top down, the first cluster (Figure $5 \mathrm{~A}$ ), it is comprised by most genotypes expressing positive and greater responses for carbon isotope discrimination (CID) in alternate wetting and drying (AWD), compared to response of these same genotypes in continuous flooding (CF). Interestingly, under AWD, BRS Pampeira and LTB 17033 displayed above average values for carbon isotope discrimination closely to total root volume and root length, all of them at the end of the third irrigation cycle. Moreover, most genotypes from this cluster highlight highest values for stomatal density and stomatal pore width. Even arranged in other clusters, these genotypes keep positive responses for these same root traits since the first irrigation cycle, indicating their constitutive character (Figure 5 B). As emphasized in the methodological topic, stomatal density and stomatal pore width were measured only at AWD in first intermittent cycle due to their high demand in human resources and time.

CTB 1419, BRS 358, LTB 1306, LTB 13016, CAN 1120 and CTB 1144 comprise the second cluster for genotypes subjected to AWD. In this cluster (under AWD - Figure 4 A) most of the genotypes show negative values relative to stomatal density and stomatal pore width with reduced performance for most evaluated root traits, besides of their reduced capacity for effective use of water as shown by low carbon isotope discrimination responses. Differently from the second cluster, the third included most genotypes, even those with reduced CID capacity (with positive responses for total root volume and root length at first irrigation cycle), their root responses changed at third evaluation with negative performance for most of measured root traits.

Figure 4 Heat map analysis of root architecture, physiological, shoot morphological and micromorphological traits, subjected to alternate wetting drying $(A)$ and to continuous flooding (B) regimes

Obviously, attributing to only one or a few traits to justify the superior performance of a given genotype, subjected to AWD, would lead to a somewhat reductionist conclusion. On the other hand, it is well documented that genetic differences in rice root architecture and rooting depth may contribute to maintain higher stomatal conductance and, at the same time, allow them an increase in $\mathrm{CO}_{2}$ influx helping to sustain a higher photosynthetic rate in plant grown under limited water availability. Taken together, geneticists, breeders and physiologist are in consensus that the breeding plants showing root 
traits that result in improvements of grain productivity under limited water availability, should include long specific root length, root volume and changes in their diameter (plasticity), especially at depth with available water at deep soil profile (Yang et al. 2012; Comas et al. 2013).

In summary, standardized phenotypic values presented by heatmap indicates that genotypes with increased root length and volume at the end of the third irrigation cycle, were the ones who also showed positive responses to stomatal conductance, as pointed by their greater carbon isotope discrimination. From top down, the first cluster under AWD (Figure $4 \mathrm{~A}$ ), draws attention to the fact that most genotypes highlighting positive values for stomatal density and stomatal pore width, were the ones that also showed increased total root volume and total root length, regardless of the irrigation cycle.

Stomata plays a fundamental regulation role in the trade-off between $\mathrm{CO}_{2}$ influx and water efflux. However, recent advances have shown also their interaction with below-ground development or their contribution in the diffusion of other gases (Mohammed et al. 2019). These authors surprisingly found that rice root cortical aerenchyma is formed constitutively in plants overexpressing OSEPF1, a gene involved in the reduction of stomatal densities. In this sense, it should be considered that in the shortterm, water loss is controlled as a dynamic change in the degree of stomatal openness; on the other hand, the stomatal density will determine this water loss in the long-term. As pointed before, positive root architecture responses (cluster 1 genotypes from top down, under AWD) were associated to superior physiological performance (roots with increased capacity to capture soil moisture). Furthermore, higher carbon isotope discrimination capacity leads to a definition of the traits that may promote significant contributions to plant ideotypes when AWD is adopted.

When breeders aim to select plants based on higher CID under continuous flooding irrigation $\left(\mathrm{h}^{2}=0.85\right)$, at least one of these, such as root total volume $\left(h^{2}=0.75\right)$ and/or their total root length $\left(h^{2}=0.70\right)$, will be probably improved. Under AWD, prioritizing the selection of those showing higher CID will also select increased root volume and length, AWD cycle number. Under AWD, BRS Pampeira and LTB 17033 are highlighted with positive responses for carbon isotope fractionation in the two irrigation methods. Interestingly, while BRS Pampeira shows greater stomatal density with lower stomatal pore width, LTB 17033 exhibits larger stomatal pore width associated to smaller stomatal density (Figure 4 A). Pore size has been the main determinant in the stomatal conductance (Fanourakis et al. 2015). It is already well consolidated that variation in anatomical features of stomata, as stomatal pore width and their regulation, may lead to impacts on gas exchange (Aliniaeifard and van Meeteren 2014; Giday et al. 2014). Moreover, stomatal conductance performance can be changed by variation in stomatal density, size or even by percentage of pore area per stomatal area. Increased stomatal size generally leads to increases in stomatal conductance due to associations with larger pores (Franks and Farquhar 2007). The contrasting behavior evidenced by these two genotypes (BRS Pampeira and LTB 17033) for water use regulation are also adopted by CNA 1003 and BRS Pampa CL, from the same cluster (Figure 5 4), even that in different magnitudes.

\section{Conclusions}


There is significant genotypic variability for CID in rice leaves, among the evaluated genotypes, regardless of cycles number in AWD irrigation. This approach demonstrated the plausibility of using CID as tracer with relatively high-throughput to early select genotypes with increased root volume and length, and higher stomatal conductance. Although this is a preliminary evidence in supporting this idea, the next step will focus on contrasting CID with the other traits in field conditions. In the next step, this validation will provide important insight into the robustness of the hypotheses presented in this work. We believe that it will be confirmed the root morphology behavior and gas exchange performance as being associated to CID in rice leaves, as well as to grain yield components.

\section{References}

1. Aliniaeifard S, van Meeteren U (2014) Natural variation in stomatal response to closing stimuli among Arabidopsis thaliana accessions after exposure to low VPD as a tool to recognize the mechanism of disturbed stomatal functioning. J Exp Bot 65(22):6529-6542. doi:10.1093/jxb/eru370

2. Bouman B (2009) How much water does rice use? Rice Today 8:28-29

3. Brand WA, Coplen TB (2012) Stable isotope deltas: tiny, yet robust signatures in nature. Isot Environ Health Stud 48:393-409. doi:https://doi.org/10.1080/10256016.2012.666977

4. Brito GG, Caixeta ET, Gallina AP, Zambolim EM, Zambolim L, Diola V, Loureiro ME (2010) Inheritance of coffee leaf rust resistance and identification of AFLP markers linked to the resistance gene. Euphytica 173(2):255-264. doi:10.1007/s10681-010-0119-x

5. Brito GG, Fagundes PRR, Andres A, Silva JT, Pazini J, Parfit JMB (2019) Plasticity in Root Length and Volume Through the Alternate Wetting and Drying Water Management in rice. J Agric Sci 11(4):1-12

6. Brito GG, Suassuna ND, Diola V, Sofiatti V, Ducatti C, Silva ET, Morello CL (2014) Carbon isotope fractionation for cotton genotype selection. Pesquisa Agropecuária Brasileira 49(09):673-682. doi:10.1590/S0100-204X2014000900003

7. Brugnoli E, Hubick KT, von Caemmerer S, Wong SC, Farquhar GD (1988) Correlation between the Carbon Isotope Discrimination in Leaf Starch and Sugars of C(3) Plants and the Ratio of Intercellular and Atmospheric Partial Pressures of Carbon Dioxide. Plant physiology 88(4):1418-1424

8. Carrijo DR, Lundy ME, Linquist BA (2017) Rice yields and water use under alternate wetting and drying irrigation: A meta-analysis. Field Crops Research 203:173-180.

doi:https://doi.org/10.1016/j.fcr.2016.12.002

9. Comas LH, Becker SR, Cruz VM, Byrne PF, Dierig DA (2013) Root traits contributing to plant productivity under drought. Front Plant Sci 04(05):1-16.

doi:https://doi.org/10.3389/fpls.2013.00442

10. Coplen TB (2011) Guidelines and recommended terms for expression of stable-isotope-ratio and gasratio measurement results. Rapid Commun Mass Spectrom 25(17):2538-2560.

doi:https://doi.org/10.1002/rcm.5129 
11. Core R, Team T (2020) R: A Language and Environment for Statistical Computing. Viena, Austria

12. Counce PA, Keisling TC, Mitchell AJ (2000) A Uniform, Objective, and Adaptive System for Expressing Rice Development. Crop Sci 40(2):436-443. doi:https://doi.org/10.2135/cropsci2000.402436x

13. Covarrubias-Pazaran G (2016) Genome-Assisted Prediction of Quantitative Traits Using the R Package sommer. PLOS ONE 11(6):e0156744. doi:10.1371/journal.pone.0156744

14. Covarrubias Pazaran G (2018) Software update: Moving the R package sommer to multivariate mixed models for genome-assisted prediction. doi:10.1101/354639

15. Dallastra, Unêda-Trevisoli SH, Ferraudo AS, Di Mauro AO (2014) Multivariate approach in the selection of superior soybean progeny which carry the RR gene. Revista Ciência Agronômica 45(3):588-597

16. Diola V, de Brito GG, Caixeta ET, Maciel-Zambolim E, Sakiyama NS, Loureiro ME (2011) High-density genetic mapping for coffee leaf rust resistance. Tree Genetics Genomes 7(6):1199-1208. doi:10.1007/s11295-011-0406-2

17. Dixon L, Carter AH (2019) Toward a New Use for Carbon Isotope Discrimination in Wheat Breeding. Agronomy 9(385):1-11. doi:http://dx.doi.org/10.3390/agronomy9070385

18. Fan S, Brzeska J (2014) Feeding More People on an Increasingly Fragile Planet: China's Food and Nutrition Security in a National and Global Context. Journal of Integrative Agriculture 13(6):11931205. doi:https://doi.org/10.1016/S2095-3119(14)60753-X

19. Fanourakis D, Giday H, Milla R, Pieruschka R, Kjaer KH, Bolger M, Vasilevski A, Nunes-Nesi A, Fiorani F, Ottosen C-O (2015) Pore size regulates operating stomatal conductance, while stomatal densities drive the partitioning of conductance between leaf sides. Ann Bot 115(4):555-565. doi:10.1093/aob/mcu247

20. Farquhar G, Richards R (1984) Isotopic Composition of Plant Carbon Correlates With Water-Use Efficiency of Wheat Genotypes. Funct Plant Biol 11(6):539-552. doi:https://doi.org/10.1071/PP9840539

21. Farquhar GD, Ehleringer JR, Hubick T K (1989) Carbon Isotope Discrimination and Photosynthesis. Annu Rev Plant Physiol Plant Mol Biol 40:503-537. doi:https://doi.org/10.1146/annurev.pp.40.060189.002443

22. Franks PJ, Farquhar GD (2007) The mechanical diversity of stomata and its significance in gasexchange control. Plant physiology 143(1):78-87. doi:10.1104/pp.106.089367

23. Giday H, Fanourakis D, Kjaer KH, Fomsgaard IS, Ottosen CO (2014) Threshold response of stomatal closing ability to leaf abscisic acid concentration during growth. J Exp Bot 65(15):4361-4370. doi:10.1093/jxb/eru216

24. Hall AE, Richards RA, Condon AG, Wright GC, Farquhar GD (1994) Carbon Isotope Discrimination and Plant Breeding. In: Plant Breeding Reviews. pp 81-113. doi:https://doi.org/10.1002/9780470650493.ch4

25. Holland JB (2006) Estimating Genotypic Correlations and Their Standard Errors Using Multivariate Restricted Maximum Likelihood Estimation with SAS Proc MIXED. Crop Sci 46(2):642-654. 
doi:https://doi.org/10.2135/cropsci2005.0191

26. Jacquemin J, Bhatia D, Singh K, Wing RA (2013) The International Oryza Map Alignment Project: development of a genus-wide comparative genomics platform to help solve the 9 billion-people question. Curr Opin Plant Biol 16(2):147-156. doi:10.1016/j.pbi.2013.02.014

27. Kolde R (2019) Implementation of heatmaps that offers more control over dimensions and appearance. https://cran.r-project.org/web/packages/pheatmap/index.html. Accessed December, 14th, 20202020

28. Mohammed U, Caine RS, Atkinson JA, Harrison EL, Wells D, Chater CC, Gray JE, Swarup R, Murchie EH (2019) Rice plants overexpressing OsEPF1 show reduced stomatal density and increased root cortical aerenchyma formation. Sci Rep 9(1):5584. doi:10.1038/s41598-019-41922-7

29. Pinto MAB, Parfit JMB, Timm LC, Faria LC, Scivittaro WB (2016) Sprinkler-irrigated rice yield in lowlands as a function of water availability and soil attributes. Pesquisa Agropecuária Brasileira 51(9):1584-1593. doi:http://dx.doi.org/10.1590/S0100-204X2016000900058

30. Pinto MAB, Parfitt JMB, Timm LC, Faria LC, Concenço G, Stumpf L, Nörenberg BG (2020) Sprinkler irrigation in lowland rice: Crop yield and its components as a function of water availability in different phenological phases. Field Crops Research 248:107714. doi:https://doi.org/10.1016/j.fcr.2020.107714

31. Price AH, Norton GJ, Salt DE, Ebenhoeh O, Meharg AA, Meharg C, Islam MR, Sarma RN, Dasgupta T, Ismail AM, McNally KL, Zhang H, Dodd IC, Davies WJ (2013) Alternate wetting and drying irrigation for rice in Bangladesh: Is it sustainable and has plant breeding something to offer? Food Energy Security 2(2):120-129. doi:10.1002/fes3.29

32. Raza A, Razzaq A, Mehmood SS, Zou X, Zhang X, Lv Y, Xu J (2019) Impact of Climate Change on Crops Adaptation and Strategies to Tackle Its Outcome: A Review. Plants (Basel) 8(2):34. doi:10.3390/plants8020034

33. Sandhu N, Raman KA, Torres RO, Audebert A, Dardou A, Kumar A, Henry A (2016) Rice Root Architectural Plasticity Traits and Genetic Regions for Adaptability to Variable Cultivation and Stress Conditions. Plant physiology 171(4):2562-2576. doi:10.1104/pp.16.00705

34. Santos HG, Jacomine PKT, Anjos LHC, Oliveira VA, Lumbreras JF, Coelho MR (2018) Sistema Brasileiro de Classificação de Solos, vol 5. Brasília, DF

35. SigmaPlot (Version 14.0) Systat Software, Inc., San Jose California USA., 14.0 edn. Systat Software, San Jose California USA

36. SOSBAI (2018) Recomendações técnicas da pesquisa para o sul do Brasil, vol 31. Reunião Técnica da Cultura do Arroz Irrigado. SOSBAI, Bento Gonçalves

37. Tedesco MJ, Gianello C, Bissani CA, Bohnen H, Volkweiss SJ (1995) Análise de solo, plantas e outros materiais, vol 5, 2 edn. Departamento de Solos da UFRGS, Porto Alegre

38. Weber RL, Wiebke-Strohm B, Bredemeier C, Margis-Pinheiro M, de Brito GG, Rechenmacher C, Bertagnolli PF, de Sa ME, Campos Mde A, de Amorim RM, Beneventi MA, Margis R, Grossi-de-Sa MF, 
Bodanese-Zanettini MH (2014) Expression of an osmotin-like protein from Solanum nigrum confers drought tolerance in transgenic soybean. BMC Plant Biol 14:343. doi:10.1186/s12870-014-0343-y

39. Yang J-c, Zhang H, Zhang J-h (2012) Root Morphology and Physiology in Relation to the Yield Formation of Rice. Journal of Integrative Agriculture 11(6):920-926.

doi:https://doi.org/10.1016/S2095-3119(12)60082-3

\section{Figures}

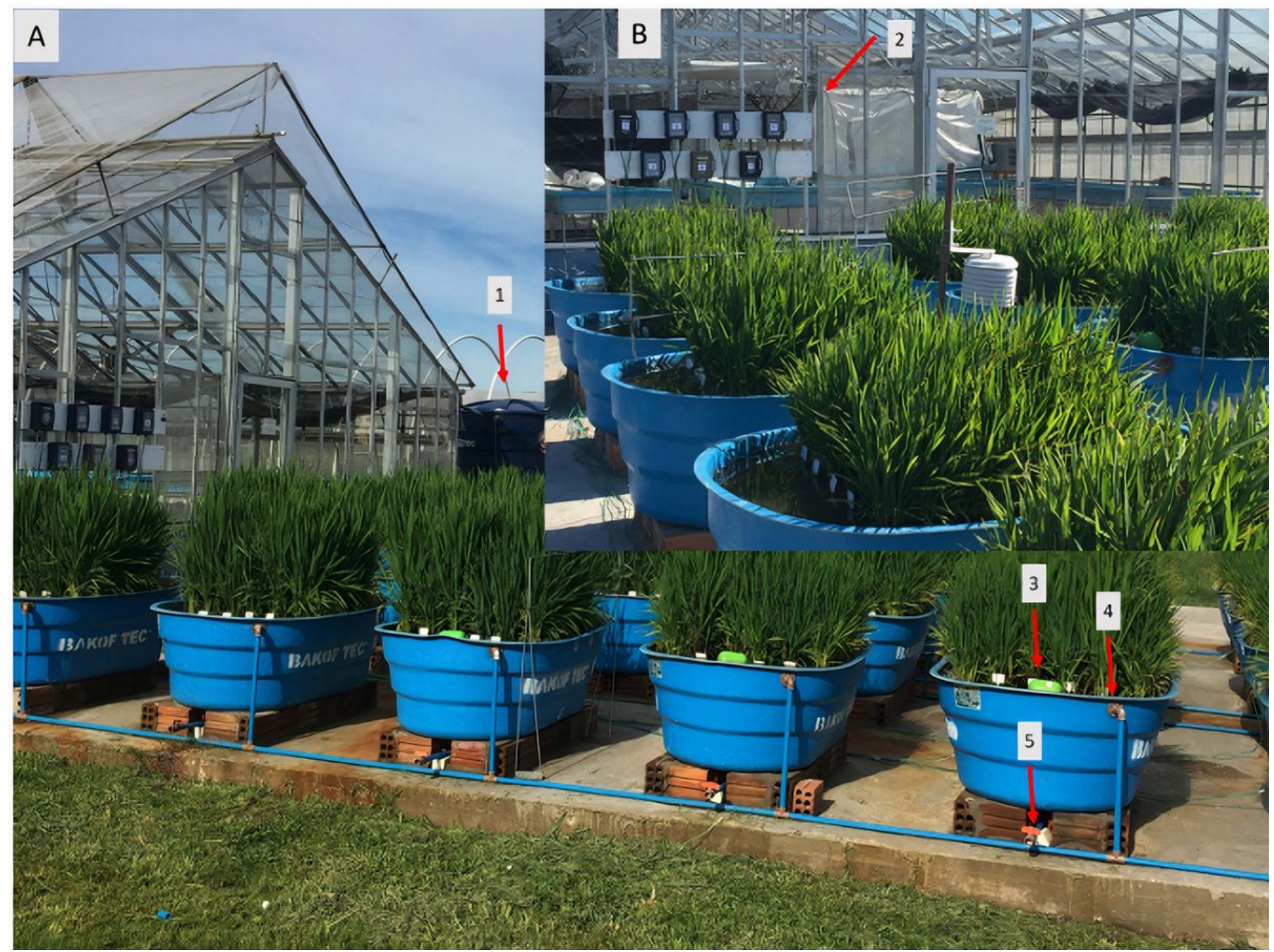

Figure 1

Overview of a low-cost structure facility specifically designed and constructed for monitoring and efficient control of the alternate wetting and drying cycles during the study; red arrows indicate rainwater reservoir (1), data loggers for soil tension monitoring and logging (2), float-controlled layer valve (3), water inlet controller (4) and water drainage controller (5) 


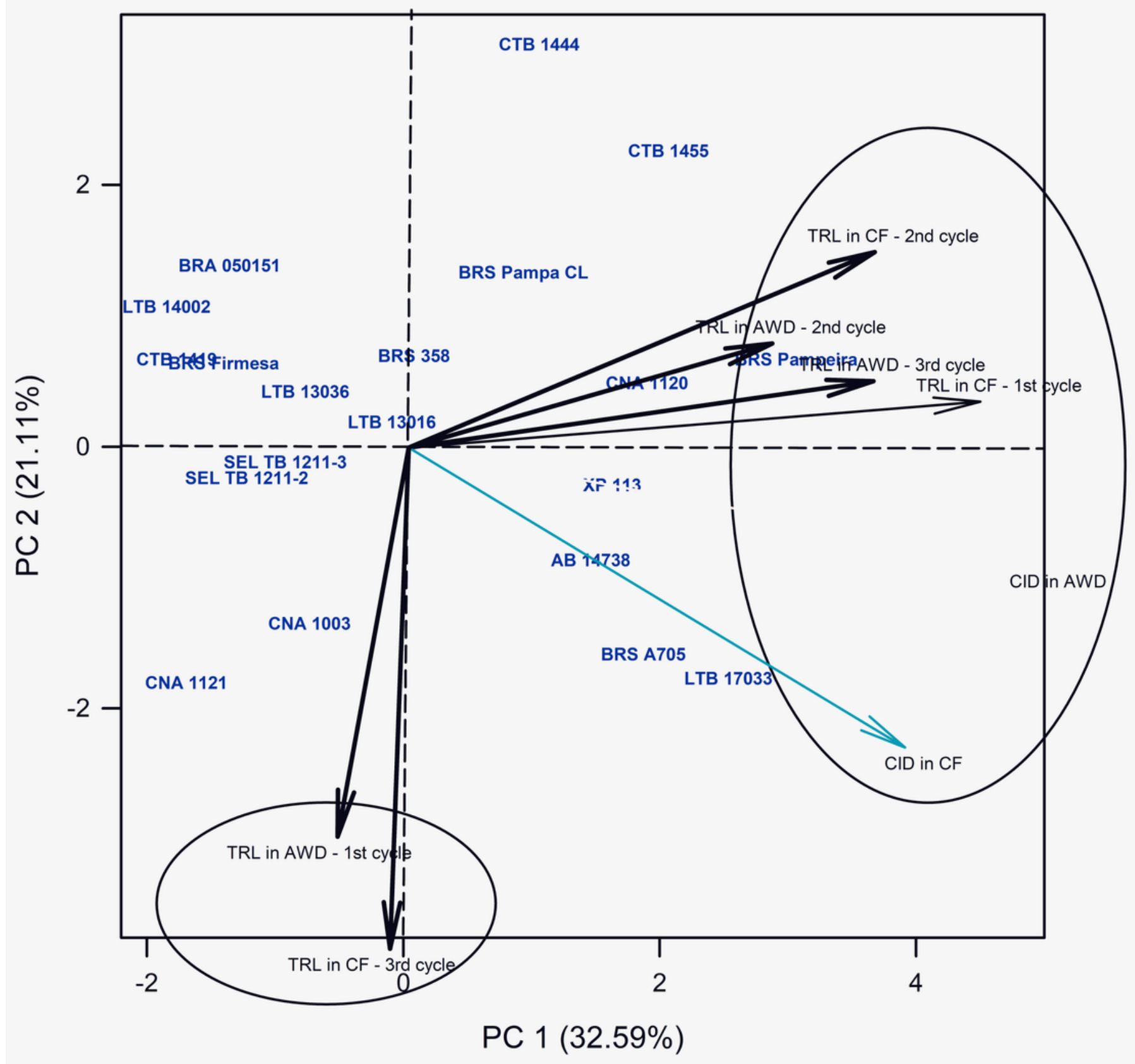

Figure 2

PCA of the eight variables/derivatives involving total root length (TRL in $\mathrm{cm}$ ) at three irrigation cycles and carbon isotope discrimination subjected to two-water regime treatments. The first two components show majority of variation with their vector projections for each trait. Biplot graph highlight the genotypes distribution (in dark blue) across worked scales. The traits marked by circles/ellipses contributed more to the variation explained by PC1, and to the variation explained by PC2. Blue and Red arrows denote carbon isotope discrimination under continuous flooding and under alternate wetting and drying water regimes, 
respectively; other trait labels are in according to category (uppercase letters) in Table 3; together with their acronyms

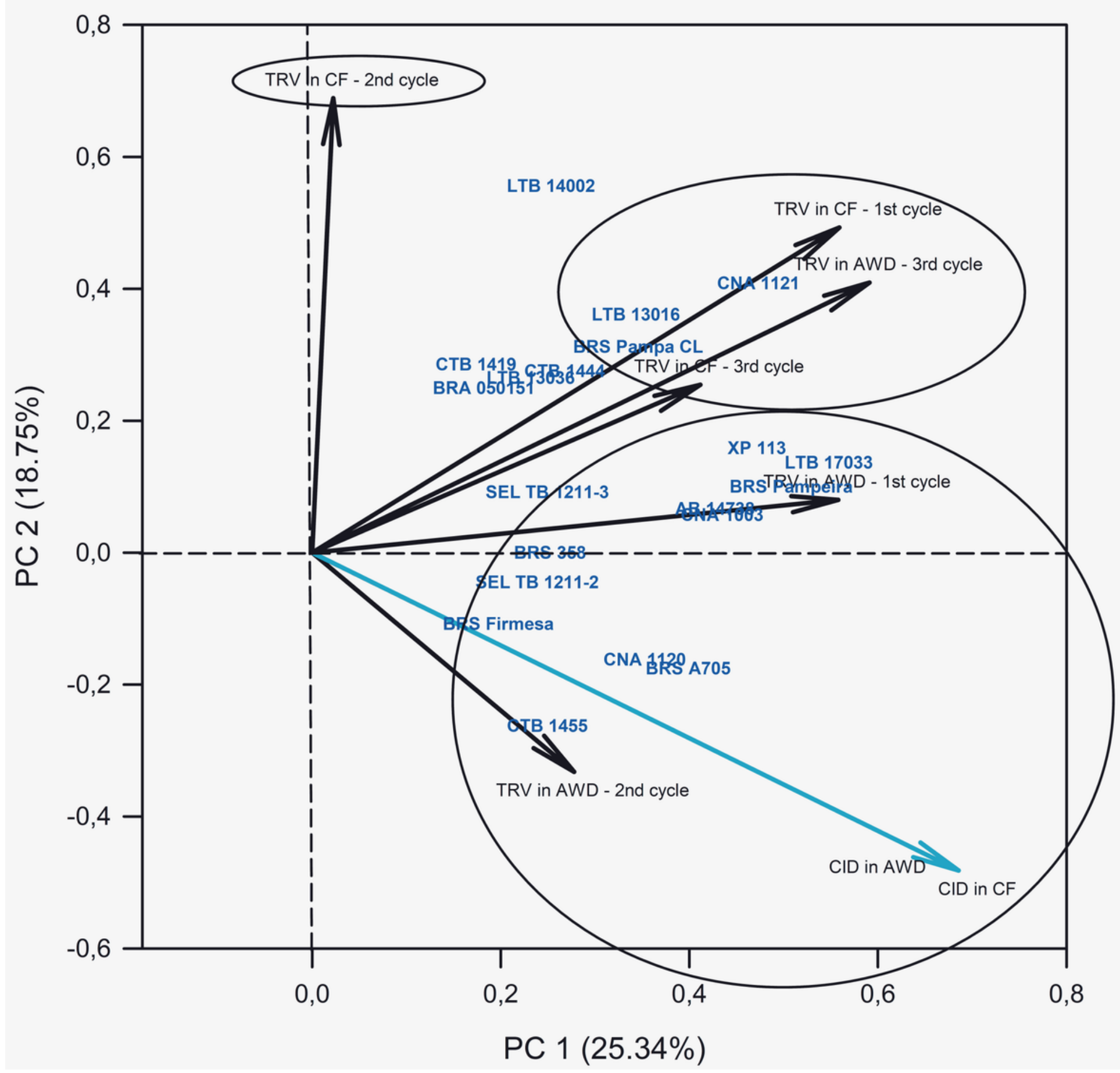

Figure 3

PCA of the eight variables/derivatives involving total root length (TRV in cm-3) at three irrigation cycles and carbon isotope discrimination (CID) subjected to two-water regime treatments. The first two components show majority of variation with their vector projections for each trait. Biplot graph highlight the genotypes distribution (in dark blue) across worked scales. The traits marked by circles/ellipses 
contributed more to the variation explained by PC1, and to the variation explained by PC2. Blue and Red arrows denote carbon isotope discrimination under continuous flooding and under Alternate wetting and drying water regimes, respectively; other trait labels are in according to category (uppercase letters) in Table 3; together with their acronyms

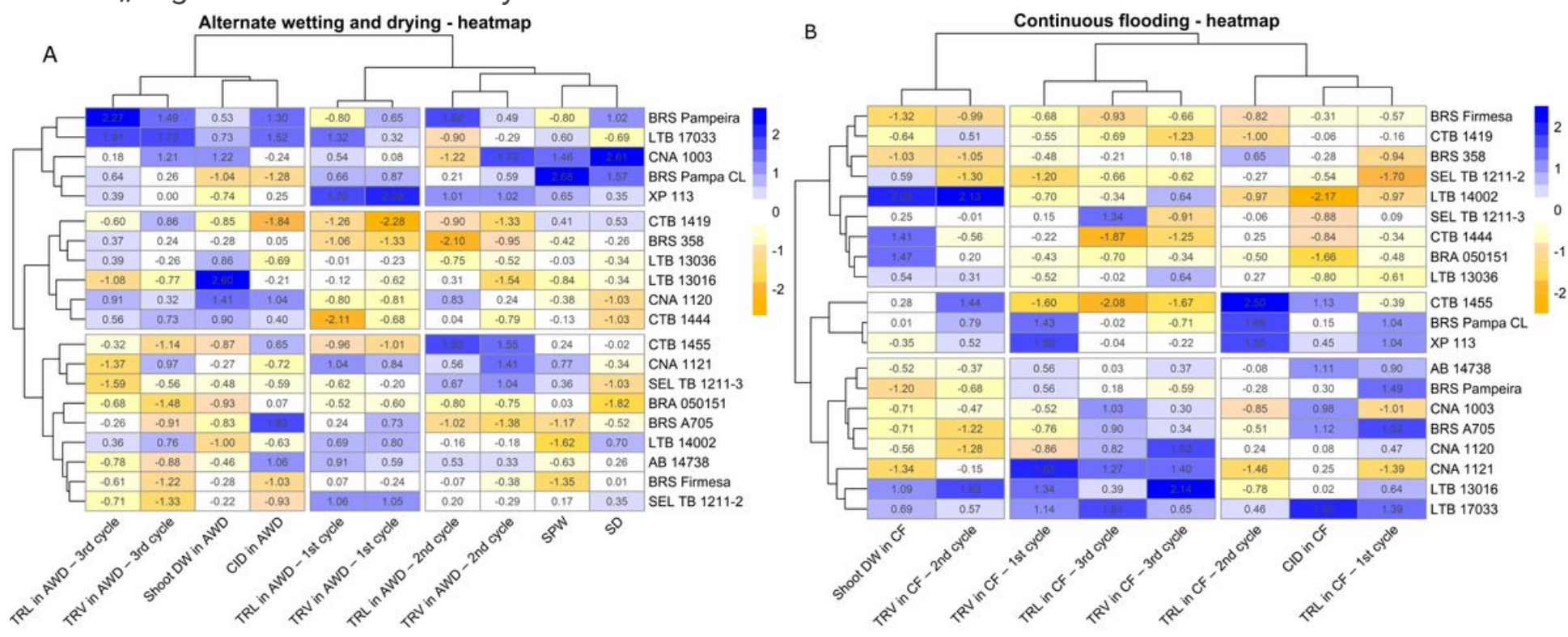

\section{Figure 4}

Heat map analysis of root architecture, physiological, shoot morphological and micro-morphological traits, subjected to alternate wetting drying $(A)$ and to continuous flooding (B) regimes 